\title{
Outcomes in Schatzker Type 5 and Type 6 Tibial Plateau Fractures Treated with Ilizarov External Fixator: Follow-up in 30 Patients
}

\author{
Anubhav Verma ${ }^{1, \oplus}$ Sheshagiri Venkateshaiah ${ }^{1} \quad$ Siddalingamurthy Gajapurada ${ }^{1}$ \\ ${ }^{1}$ Department of Orthopedics, JSS Hospital, Mysore, \\ Address for correspondence Anubhav Verma, MS, Department of \\ Orthopedics, JSS Hospital, G132 Brigade Sparkle, JP Nagar, Mysore, \\ Karnataka 570008, India (e-mail: anubhavlucky@gmail.com).
}

Int J Recent Surg Med Sci 2020;6:4-11

\begin{abstract}
Keywords

- tibial plateau

- Schatzker type 5 and 6

- llizarov external fixator

Introduction Fractures of the proximal tibia, particularly those that extend into the knee joint, are serious injuries that frequently result in functional impairment. Complications include infection, compartment syndrome, stiffness, skin loss, and possible amputation. These can be minimized using the llizarov external fixator which allows early weight bearing, minimal soft tissue injury, and a multiaxial stable fixation.

Materials and Methods A total of 30 patients with open/closed Schatzker type 5 and 6 tibial plateau fractures were studied for outcome following surgery and implant removal using the modified Hohl and Luck criteria which include functional (extensor lag, valgus or varus instability, knee range of movement, walking distance and pain) and radiological parameters (valgus/varus deformity, depression of articular surface, and osteoarthritis).

Results In our study, out of 30 patients $53.3 \%$ patients had an excellent outcome functionally, whereas $23.3 \%$ had a good outcome, $13.3 \%$ fair, and $10 \%$ had a poor outcome. Radiologically, $46.6 \%$ had an excellent outcome, $40 \%$ had a good outcome, and $13.3 \%$ had a fair outcome. All the patients achieved union with a mean time of 23.9 weeks. Common complication was pin tract infection in $13.3 \%$ patients. In total, $60 \%$ of the patients could be mobilized immediately with the remaining mobilized within 1 to 4 weeks.

Conclusion Most patients had an excellent to good functional or radiological outcome once the implant was removed. Weight bearing could be started immediately in most cases with minimal complications encountered in few patients like pin tract infection, deep venous thrombosis, and osteomyelitis.
\end{abstract}

\section{Introduction}

Fractures of the proximal tibia, particularly those that extend into the knee joint are serious injuries that frequently result in functional impairment. In the past 3 decades, with improvements in surgical techniques and implants, there has been an unmistakable trend toward surgical management of these injuries. Nevertheless, proximal tibial fractures remain challenging because of their number, variety, and complexity. Despite a plethora of articles, written in the past 50 years, that have addressed the problems of classification and results
DOI https://doi.org/

10.1055/s-0040-1701555

ISSN 2455-7420. of various treatments, the optimal method of management remains controversial. ${ }^{1-3}$ The indications of nonoperative versus operative treatment vary widely among surgeons, as do the specific methods of treatment for the many fracture configurations.

The spectrum of injuries to the tibial plateau is so great that no single method of treatment has proven uniformly successful. ${ }^{4}$ The stationary lower limb may be struck by a moving object, the common pedestrian injury, the so called bumper fractures. This is because the bumper of most of the 
vehicles is roughly placed at knee height. The exposed knee joint may be subjected to angulation, rotation, and shearing strains and when the subject is upright, the body weight assists in the injury.

The need for this study lies in the advantages of the Ilizarov circular external ring fixator. Minimal use of hardware, stable multiaxial fixation, ease of application, and early return to mobility are few of the major advantages which form the basis of this study.

\section{Materials and Methods}

The design of the study was prospective with the study period beginning from April 2014 to May 2016 with a minimum follow-up period of 6 months.

Persons aged between 18 and 75 years of either sex with Schatzker type 5 (-Fig. 1 ) or type 6 tibial plateau fracture either closed or open falling under any grade of the Gustillo-Anderson classification were included in the study.

Persons with age less than 18 or more than 75 with Schatzkers type 1 to type 4 tibial plateau fractures or patients with concomitant distal femoral fractures were excluded from the study.

Thirty patients were included in the study. On admission, a structured proforma was filled assessing the fracture configuration and a head to toe examination. Fractures were assessed using appropriate X-rays only. Informed consent for all patients was taken along with an ethical committee approval. Patients were appropriately counseled regarding the various modalities of treatment and only those who opted for this modality were included in the study. All patients were operated within 1 week from the time of injury depending on anesthetic fitness and skin condition (edema/skin blebs). In case of open proximal tibial fracture, a thorough debridement with $5 \%$ povidone iodine solution and normal saline was given in the operation theater under spinal or general anesthesia followed by fixation of the fracture.

Standard operative technique was followed with $\boldsymbol{-}$ Fig. 2 showing immediate postop X-ray with frame in situ.

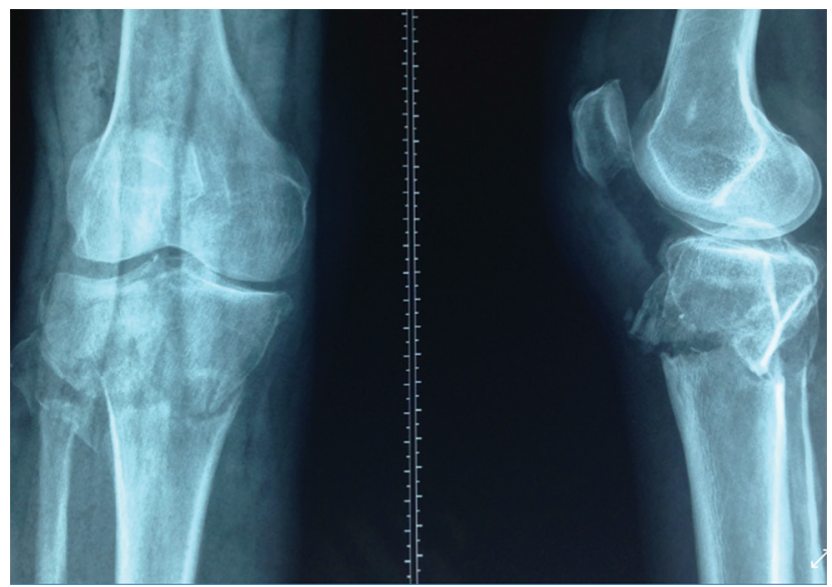

Fig. 1 X-ray showing Schatzker type 5 bicondylar fracture.
Final radiological and functional assessment was done following fixator removal. Fractures were regarded as being healed when anteroposterior and lateral radiographs showed a bridging callus of three of four cortices and/or the fracture was stable when stressed manually and the patients were able to walk without pain after the connecting rods had been removed ( - Fig. 3). ${ }^{5}$ Denis modification of Hohl and Luck criteria was used to assess the final outcome ${ }^{6}$ (- Tables 1 and $\mathbf{2}$ ).

\section{Results}

Demographic and incidence analyses were done. Correlation between various variables was done using the Pearson correlation. The value of chi-square was calculated. A $p$-value of less than 0.05 was considered to be significant.

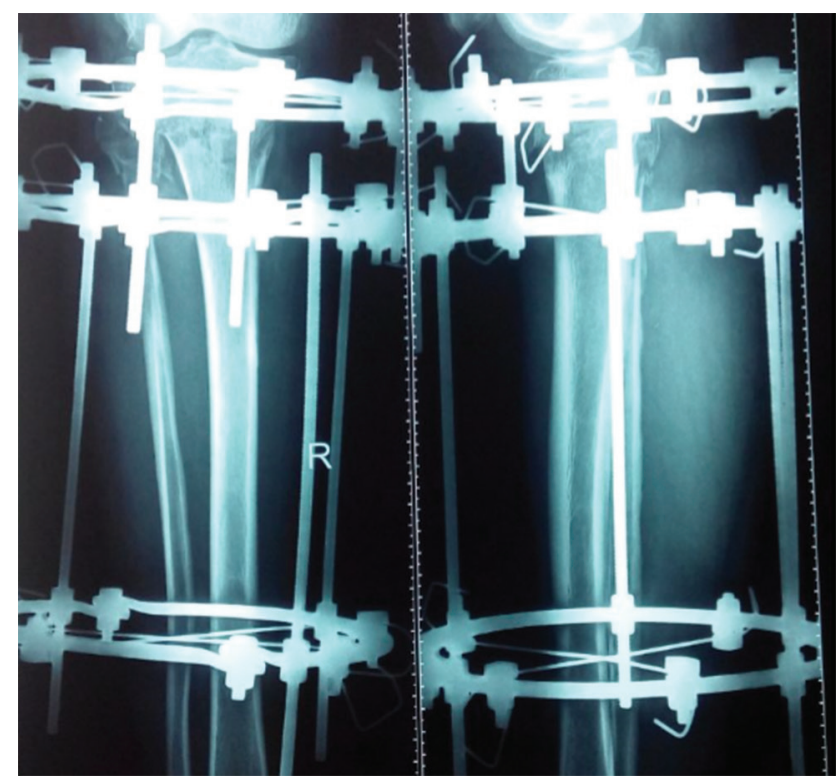

Fig. 2 Postoperative X-ray with llizarov frame in situ.

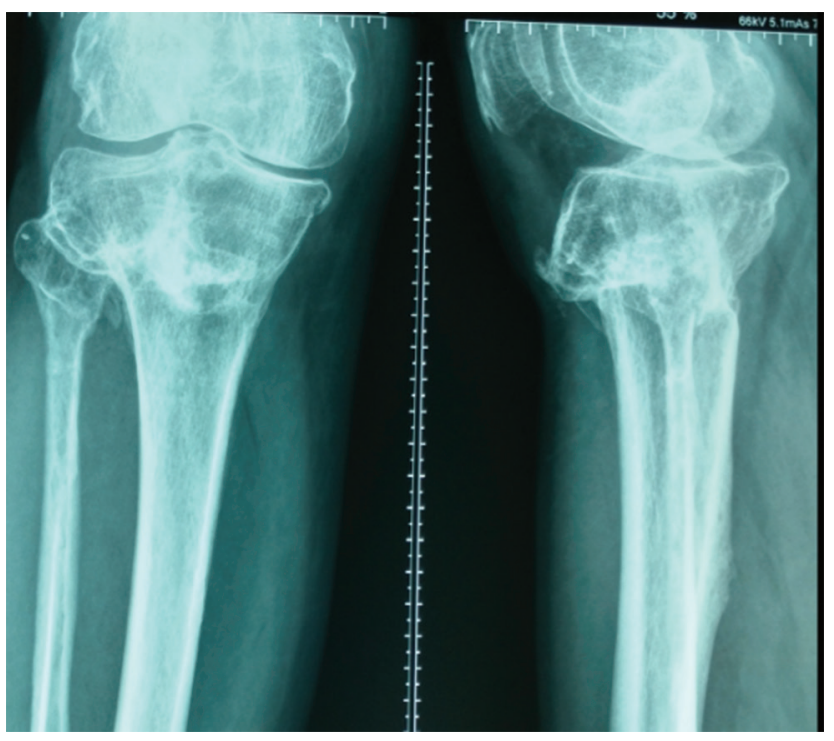

Fig. 3 X-ray showing union following implant removal. 
Table 1 Functional grading used in the evaluation

\begin{tabular}{|l|l|l|l|l|l|}
\hline Grade & $\begin{array}{l}\text { Lack of extension } \\
\text { (degrees) }\end{array}$ & $\begin{array}{l}\text { Range of } \\
\text { movement } \\
\text { (degrees) }\end{array}$ & $\begin{array}{l}\text { Varus or valgus } \\
\text { instability } \\
\text { (degrees) }\end{array}$ & $\begin{array}{l}\text { Walking } \\
\text { distance (m) }\end{array}$ & Pain \\
\hline $\begin{array}{l}\text { Excellent (all of the } \\
\text { following) }\end{array}$ & 0 & $\geq 120$ & $<5$ & $\geq 3,000$ & None \\
\hline $\begin{array}{l}\text { Good (not more } \\
\text { than one of the } \\
\text { following) }\end{array}$ & $>0$ & $<90$ & $>5$ & $<1,000$ & Mild on activity \\
\hline $\begin{array}{l}\text { Fair (not more } \\
\text { than two of the } \\
\text { following) }\end{array}$ & $\geq 10$ & $<75$ & & $<100$ & Moderate on activity or \\
intermittent at rest
\end{tabular}

Table 2 Radiographic grading used in the evaluation

\begin{tabular}{|l|l|l|l|}
\hline Grade & $\begin{array}{l}\text { Valgus/Varus deformity } \\
\text { (degrees) }\end{array}$ & $\begin{array}{l}\text { Depression of articular } \\
\text { surface (mm) }\end{array}$ & Osteoarthritis \\
\hline $\begin{array}{l}\text { Excellent (all of the } \\
\text { following) }\end{array}$ & $\leq 5$ & $<5$ & None \\
\hline $\begin{array}{l}\text { Good (not more than } \\
\text { one of the following) }\end{array}$ & $>5$ & $>5$ & Minimal \\
\hline $\begin{array}{l}\text { Fair (not more than two } \\
\text { of the following) }\end{array}$ & $>10$ & $>5$ & Moderate \\
\hline $\begin{array}{l}\text { Poor (all results worse } \\
\text { than fair) }\end{array}$ & & & \\
\hline
\end{tabular}

The average age of the study population was 41.3 years with 15 patients above the age of 40 and 15 patients below the age of 40 . According to - Table 3, the age of the patient had no significant relation with any of the studied variables or the outcome, whether functional or radiological. ( $p>0.05)$. There were $26(86.67 \%)$ males and only four (13.33\%) females. A total of 22 (73.3\%) patients had a type 6 injury and only 8 (26.7) had a type 5 injury. According to - Table 4, the Schatzker type had a significant correlation with the nature of the fracture. Type 6 fractures were more prone to be open rather than closed. Also, type 5 fractures could be mobilized immediately, whereas all fractures mobilized within 1 week/ 2 weeks or 4 weeks were type 6 . This relation was also found to be significant. The outcome was, however, not affected depending on the Schatzker type. A total of 25 (83.3\%) patients out of 30 had an RTA and remaining five $(16.7 \%)$ had a self-fall.

Out of the 30 patients in the study 18 (60\%) could be mobilized immediately, nine (30\%) patients mobilized within 1 week, two (6.7\%) required 2 weeks and one (3.3\%) required 4 weeks. The decision for mobilization was based on the fracture anatomy, stability of fixation, general condition of patient, soft tissue condition, and the overall cooperation of the patient. According to - Table 4, mobilization of the patient had a significant correlation with the Schatzker type. All patients with type 5 injuries could be mobilized immediately. Patients with type 6 injuries tend to have late mobilization. Also, patients with open injuries were mobilized late and not immediately. However, outcome was not affected by the point at which patient was mobilized.

A total of 10 patients of the 30 studied had some form of complication. Remaining 20 (66.67\%) had an uneventful recovery with minimal or no complications. Four (13.3\%) patients had a pin tract infection. Two (6.7\%) patients were noncompliant and had an early implant removal. One (3.3\%) patient had a pin tract infection with an associated foot drop and one had an associated osteomyelitis. One (3.3\%) patient only had an osteomyelitis and one (3.3\%) had a deep venous thrombosis. According to - Table 4, patients with complications tend to have a less than excellent radiological outcome. Functional outcome, however, is not affected.

Fourteen patients (46.7\%) had an excellent radiological outcome, 12 (40\%) had a good outcome, 4 (13.3\%) had a fair outcome, and none of the patients had a poor outcome. Functionally, 16 (53.3\%) out of 30 patients had an excellent outcome. Seven (23.3\%) had a good outcome, four (13.3\%) had a fair outcome, and three (10\%) had a poor outcome. None of the studied variable had an effect on the final functional outcome in this study.

The average time for union including the noncompliant patients was 23.9 weeks. Excluding those patients the average time to union was 25.14 weeks. According to - Table 4 no correlation could be established between the time for union/implant removal and the various studied variables. The outcomes were also independent of the union time. -Figs. 4 and $\mathbf{5}$ show excellent range of motion achieved in most patients in this study. 
Table 3 Age incidence and correlation with various variables

\begin{tabular}{|c|c|c|c|c|c|}
\hline \multirow[t]{3}{*}{ Variables } & \multicolumn{4}{|c|}{ Age category } & \multirow[t]{3}{*}{$\chi^{2}$ Value ( $p$-Value) } \\
\hline & \multicolumn{2}{|c|}{$\leq 40$ y $(n=15)$} & \multicolumn{2}{|c|}{$>40$ y $(n=15)$} & \\
\hline & Frequency & $\%$ & Frequency & $\%$ & \\
\hline \multicolumn{6}{|l|}{ Mode of injury } \\
\hline RTA & 13 & 86.7 & 12 & 80.0 & \multirow[t]{2}{*}{$0.240(0.624)$} \\
\hline Self-fall & 2 & 13.3 & 3 & 20.0 & \\
\hline \multicolumn{6}{|l|}{ Schatzker type } \\
\hline 5 & 3 & 20.0 & 5 & 33.3 & \multirow[t]{2}{*}{$0.682(0.409)$} \\
\hline 6 & 12 & 80.0 & 10 & 66.7 & \\
\hline \multicolumn{6}{|l|}{ Open/Closed } \\
\hline Open & 9 & 60.0 & 2 & 13.3 & \multirow[t]{2}{*}{$7.033(0.008)$} \\
\hline Close & 6 & 40.0 & 13 & 86.7 & \\
\hline \multicolumn{6}{|l|}{ Associated injuries } \\
\hline None & 14 & 93.3 & 14 & 93.3 & \multirow[t]{3}{*}{$2.000(0.368)$} \\
\hline Patella FX & 1 & 6.7 & 0 & 0 & \\
\hline Clavicle FX & 0 & 0 & 1 & 6.7 & \\
\hline \multicolumn{6}{|l|}{ Comorbidities } \\
\hline None & 15 & 100.0 & 8 & 53.3 & \multirow[t]{4}{*}{$9.130(0.028)$} \\
\hline $\mathrm{DM}$ & 0 & 0 & 4 & 26.7 & \\
\hline $\mathrm{DM}+\mathrm{HTN}$ & 0 & 0 & 2 & 13.3 & \\
\hline $\mathrm{DM}+\mathrm{HTN}+\mathrm{IHD}$ & 0 & 0 & 1 & 6.7 & \\
\hline \multicolumn{6}{|l|}{ Mobilization } \\
\hline Immediate & 7 & 46.7 & 11 & 73.3 & \multirow[t]{4}{*}{$2.889(0.409)$} \\
\hline $1 \mathrm{wk}$ & 6 & 40.0 & 3 & 20.0 & \\
\hline $2 w k$ & 1 & 6.7 & 1 & 6.7 & \\
\hline 4 wk & 1 & 6.7 & 0 & 0 & \\
\hline \multicolumn{6}{|l|}{ Complications } \\
\hline Yes & 6 & 40.0 & 4 & 26.7 & \multirow[t]{2}{*}{$0.600(0.439)$} \\
\hline No & 9 & 60.0 & 11 & 73.3 & \\
\hline \multicolumn{6}{|l|}{ Radiological outcome } \\
\hline Poor & 0 & 0 & 0 & 0 & \multirow[t]{4}{*}{$2.476(0.290)$} \\
\hline Fair & 3 & 20.0 & 1 & 6.7 & \\
\hline Good & 7 & 46.7 & 5 & 33.3 & \\
\hline Excellent & 5 & 33.3 & 9 & 60.0 & \\
\hline \multicolumn{6}{|l|}{ Functional outcome } \\
\hline Poor & 3 & 20.0 & 0 & 0 & \multirow[t]{4}{*}{$4.143(0.246)$} \\
\hline Fair & 1 & 6.7 & 3 & 20.0 & \\
\hline Good & 3 & 20.0 & 4 & 26.7 & \\
\hline Excellent & 8 & 53.3 & 8 & 53.3 & \\
\hline
\end{tabular}

Abbreviations: DM, diabetes mellitus; HTN, hypertension; IHD, ischemic heart disease; RTA, road traffic accident.

\section{Discussion}

In today's world of speed and technology, there seems to be an incline in complex injuries to various parts of the human anatomy. The management of tibial plateau fracture has always been a subject of debate because of their variety and complexity. In the search for perfection, any treatment modality that has a varied opinion is a subject for research and study. High energy intraarticular fractures of the tibial plateau cause added management problems and remain challenging for orthopedics surgeons ${ }^{7}$ even to date.

Over the years, many classifications for tibial plateau fractures have been developed. ${ }^{2}$ All classifications are based on fracture location and degree of displacement. However, to 


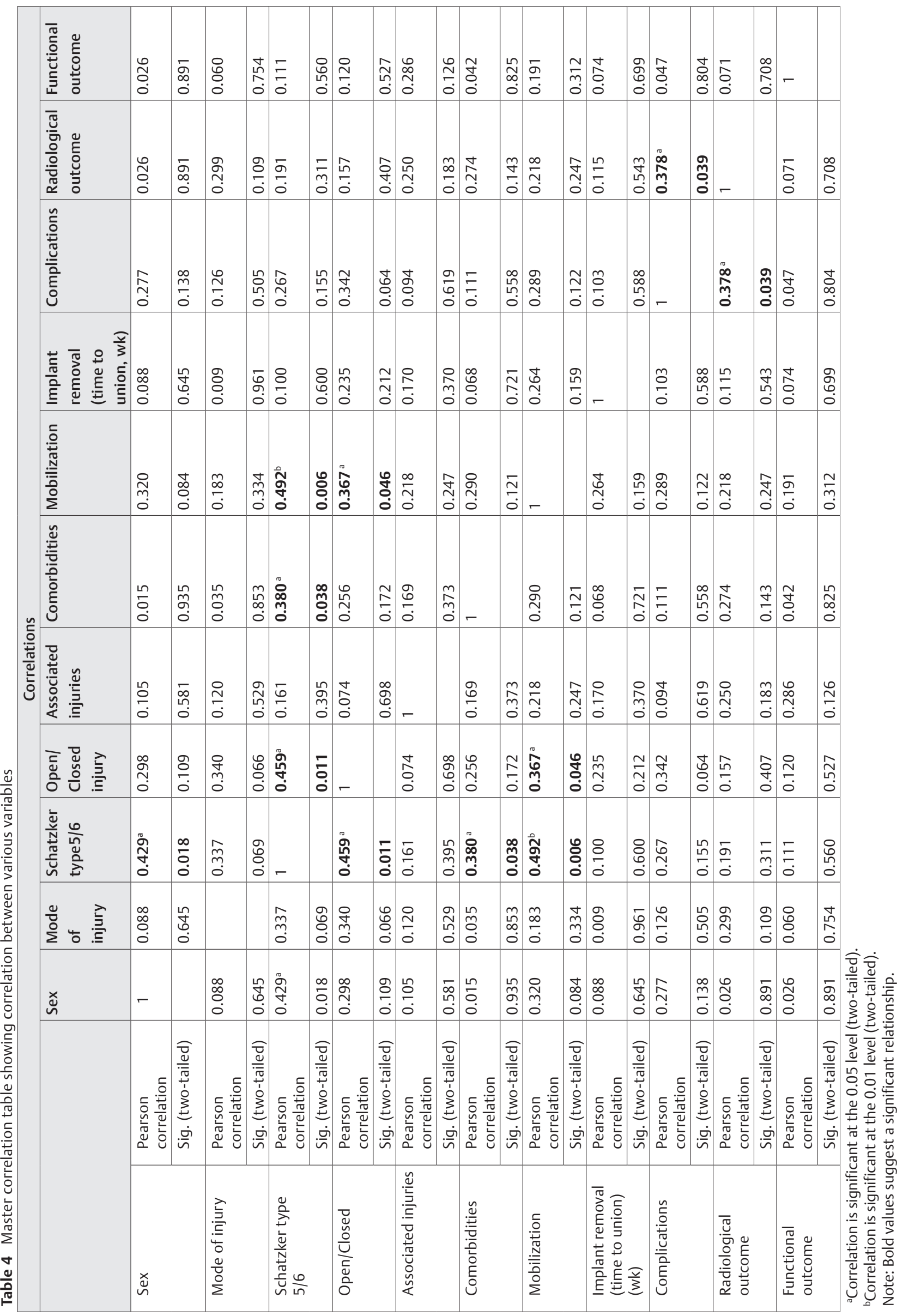




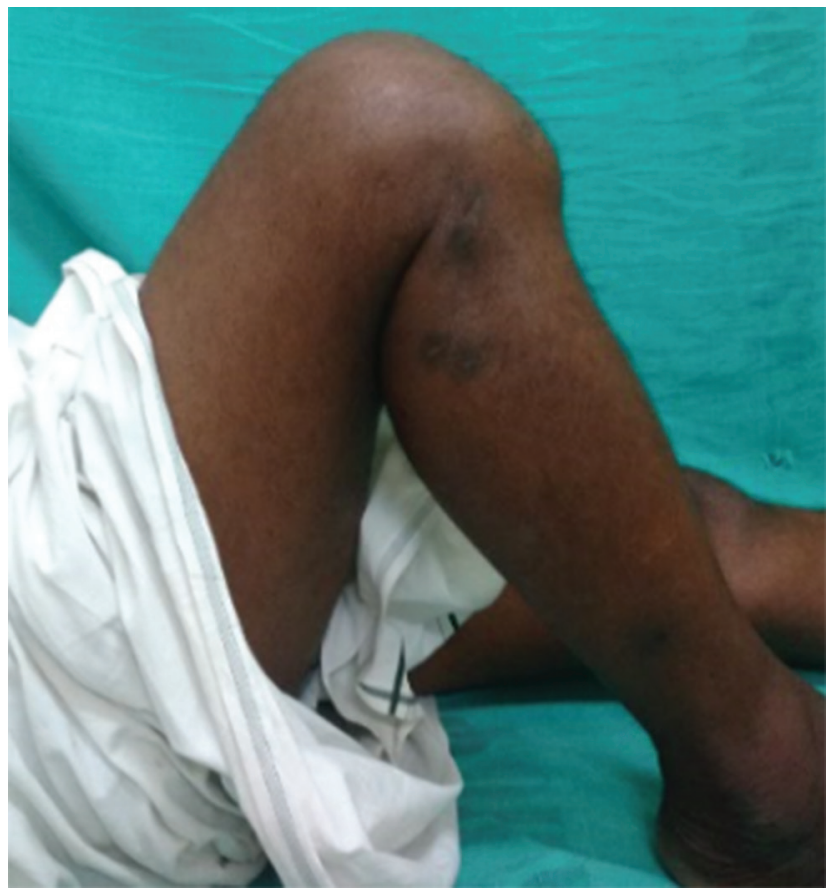

Fig. 4 Clinical picture showing near normal flexion of knee joint.

be meaningful, a classification should be simple, be easy to remember, and be relevant to both treatment and outcome.

Perhaps the most widely used classification of tibial plateau fractures is the one proposed by Schatzker. ${ }^{8-10}$ Amalgamating many of the fractures of previous classification schemes, Schatzker proposed the classification that groups these fractures into six types ( $\boldsymbol{-}$ Fig. $\mathbf{6}$ ):

1. Type 1 is a split fracture of the lateral tibial plateau without articular depression.

2. Type 2 is a split depressed fracture of the lateral tibial plateau.

3. Type 3 is an isolated depression of the lateral plateau.

4. Type 4 is a fracture of the medial plateau.

5. Type 5 is a bicondylar plateau fracture with varying degrees of articular depression and displacement of the condyles. The most common pattern is a fracture of the medial tibial condyle in association with a depressed or split depressed lateral tibial plateau fracture.

6. Type 6 is a bicondylar tibial plateau fracture with diaphyseal metaphyseal dissociation.

Ilizarov circular fixation allows both early movement and early weight bearing. The value of early movement has been well-established, ${ }^{11-14}$ but early loading of fractures of the tibial plateau has generally been avoided because of concern that the reduction may be lost, resulting in depression of the articular surface or a valgus deformity. Early weight bearing, however, stimulates bone healing and allows retention of muscular strength..$^{15-17}$ The Ilizarov tibiofemoral frame allows adequate initial weight bearing. Most treatment methods do not allow full weight bearing in intra-articular proximal tibial fractures. ${ }^{18}$ The mobilization and degree of weight bearing that is allowed is determined by the fracture displacement, method of treatment, and quality of aftercare. ${ }^{14,18}$

Ten patients of the 30 studied had some form of complication. In this study, infections were grouped into pin tract infections and osteomyelitis. Further classification into superficial and deep infections was not done. Keightley et $\mathrm{al}^{19}$ divided infections in to pin tract, superficial, and deep based on the plane of infection. They reported pin tract infection in $51.3 \%$ of their patients and no deep infections. This is significantly higher compared with our study. Ramos et $\mathrm{al}^{5}$ divided infections into pin site, pin track, and osteomyelitis. Sixteen patients out of 30 had a pin site infection, whereas two had pin track infections. None of them had osteomyelitis. This is higher compared with our study. Like our study they also had one case of deep vein thrombosis. The "Kurgan protocol" 20 was used for postoperative pin site dressings and the Checketts-Otterburns classification ${ }^{21}$ was used to describe pin tract infection. No such criteria was used in our study. Dendrinos et $\mathrm{a}^{22}$ had no case of pin track infection, septic arthritis, or osteomyelitis in the 24 cases they studied which is comparable to some other studies. ${ }^{23-25}$ In earlier series, the infection rate after treating tibial plateau fractures with open reduction and internal fixation (ORIF), varies from 6 to

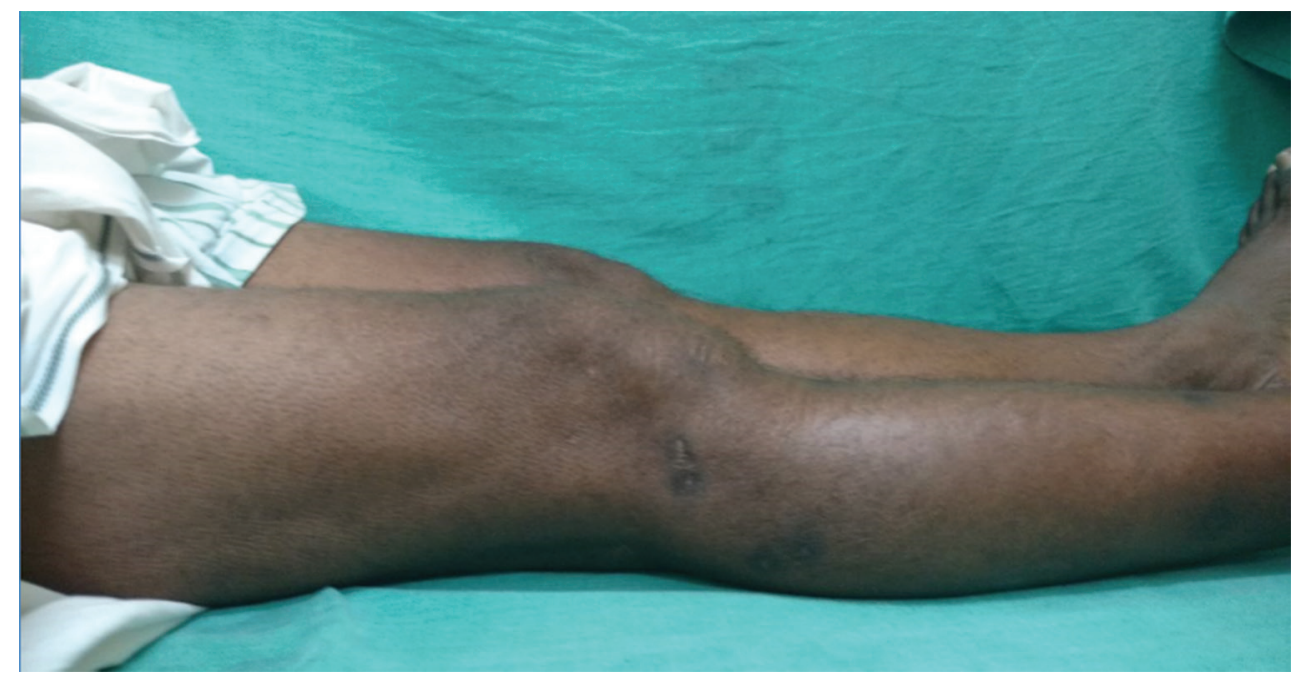

Fig. 5 Clinical picture showing full extension of knee joint. 


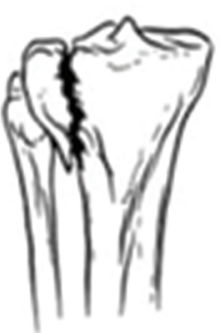

Type I Split

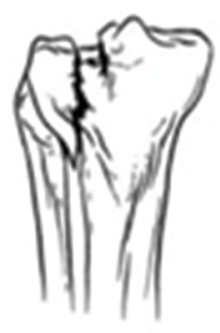

Type II

Split-depression

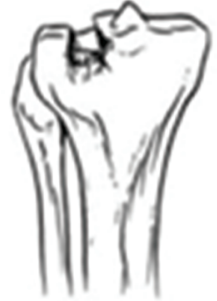

Type III

Central

depression

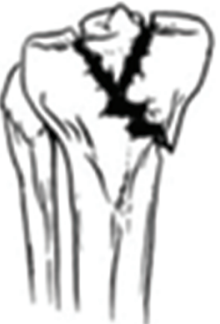

Type IV Split fracture, medial plateau

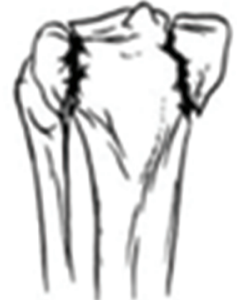

Type V

Bicondylar

fracture

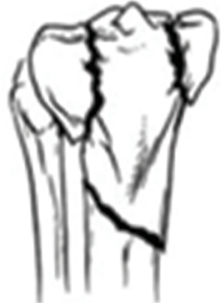

Type VI

Dissociation of

metaphysis and diaphysis

Fig. 6 Schatzker's classification.

$87.5 \% .^{26-28}$ The use of bilateral incisions and the reduction of the size of the implants have reduced this rate to 3 to $8.4 \% .^{29-31}$ Despite using a generally recommended staged protocol, Egol et $\mathrm{a}^{32}$ reported a deep wound infection rate of $5 \%$. When comparing external devices in different locations, Parameswaran et $\mathrm{a}^{33}$ reported that ring fixators had the lowest incidence of infection. Using the Ilizarov technique, Catagni et al ${ }^{34}$ did not observe any deep infections in a series of 59 patients with Schatzker V-VI fractures.

Various studies using different modalities of treatment are there in the literature. In a study by Yu et al ${ }^{35}$ which included 54 patients with tibial plateau fractures treated with ORIF with plate and screws, weight bearing was started 19 weeks after surgery and the range of motion (ROM) achieved was 0 to 108 degrees, two patients ultimately required total knee replacement. Lee et $\mathrm{al}^{36}$ operated 35 similar fractures with ORIF and started weight bearing at 12 weeks postsurgery. Deep infections were noted in two patients. Similarly, in a study by $\mathrm{Oh}$ et $\mathrm{al}^{37} 23$ patients with tibial plateau fractures were treated with ORIF and could only start weight bearing 14 weeks after surgery.

Similar studies were performed using the Ilizarov external fixator. In a study conducted by El-Barbary et a ${ }^{38}$ which included 29 patients with Schatzker type 5 and 6 fractures a median knee ROM of 0 to 112 degrees was achieved and weight bearing was started after 6 weeks with no complications. Dendrinos et $\mathrm{al}^{14}$ conducted a similar study on 24 patients with high energy tibial plateau fractures. A total of $90 \%$ patients achieved a median ROM of 110 degrees with three patients developing compartment syndrome. Weight bearing was started after 14 weeks. Thirty-three percent of the patients had an excellent outcome. Zecher et $\mathrm{al}^{39}$ in 21 patients with Schatzker type 5 and 6 tibial plateau fractures treated with circular ring fixator achieved greater than 90 degrees knee ROM in all their patients. However, seven patients developed compartment syndrome. Ramos et al ${ }^{5}$ which included 19 patients with high energy tibial plateau fractures treated with ring fixator, immediate weight bearing was started with a median range of motion of 0 to 120 degrees was achieved. Two patients needed a total knee replacement and two patients developed a compartment syndrome.
A recent study also allowed immediate weight bearing as tolerated specifically in Schatzker type 6 fractures. ${ }^{40}$ In Keightley et $\mathrm{a}^{19}$ the mean ROM achieved was 110 degrees with one patient having a fixed flexion deformity of $>10$ degrees.

The average time for union including the noncompliant patients was 23.9 weeks. Excluding those patients the average time to union was 25.14 weeks. Keightley et $\mathrm{al}^{20}$ in their study had a mean union time of 20.1 weeks which is comparable to our study. The study did have its limitations. Since there are many other modalities of treatment available, this study lacked a control group with which the results could be compared. Second, the sample size was small due to the short time period of the study. Third, follow-up was short and longterm residual effects in terms of degenerative joint diseases, daily or sports activity could not be assessed. Fourth, ligament injuries were not assessed. Similarly, X-rays were used as the only modality for preoperative, intraoperative, and postoperative assessment, although computed tomography scans have been shown to improve inter and intraobserver reliability. ${ }^{41}$ Lastly, no standard pin tract dressing protocol was followed other than the regular dressing protocols being followed at our hospital.

\section{Conclusion}

This study evaluated 30 patients with high energy Schatzker type 5 and 6 tibial plateau fractures treated with the Ilizarov circular external ring fixator. The results have been more than satisfactory with all patients achieving union. Most patients had an excellent to good functional or radiological outcome once the implant was removed. Weight bearing could be started immediately in most cases with minimal complications encountered in few patients like pin tract infection, deep venous thrombosis, and osteomyelitis.

\section{Note}

This paper was presented at Karnataka Orthopedic Association, State Conference 2017, Hubbali, Karnataka, on February 4, 2017.

\section{Conflict of Interest}

None declared. 


\section{References}

1 Gustilo RB. Fractures of the Tibial plateau. In: Gustilo RB, Kyle R, Templeman D, eds. Fractures and Dislocations. St. Louis, MO: C.V. Mosby; 1993:945

2 Honkonen SE, Järvinen MJ. Classification of fractures of the tibial condyles. J Bone Joint Surg Br 1992;74(6):840-847

3 Koval KJ, Helfet DL. Tibial plateau fractures: evaluation and treatment. J Am Acad Orthop Surg 1995;3(2):86-94

4 Waddell JP, Johnston DW, Neidre A. Fractures of the tibial plateau: a review of ninety-five patients and comparison of treatment methods. J Trauma 1981;21(5):376-381

5 Ramos T, Ekholm C, Eriksson BI, Karlsson J, Nistor L. The Ilizarov external fixator-a useful alternative for the treatment of proximal tibial fractures. A prospective observational study of 30 consecutive patients. BMC Musculoskelet Disord 2013; $14: 11-23$

6 Jensen DB, Rude C, Duus BR, Arne B-N. Tibial plateau fractures. A comparison of conservative and surgical treatment. Bone Joint Surg Br 1990;72(1):49-52

7 Raikin S, Froimson MI. Combined limited internal fixation with circular frame external fixation of intra-articular tibial fractures. Orthopedics 1999;22(11):1019-1025

8 Schatzker J. Fractures of the tibial plateau. In: Schatzker J, Tile M, eds. Rationale of Operative Fracture Care. Berlin: Springer-Verlag; 1987:279-295

9 Schatzker J. Tibial plateau fractures. In: Browner BD, Jupiter JB, Levine AM, Trafton PG, eds. Skeletal Trauma. Philadelphia, PA: W.B. Saunders; 1992:1745-1770

10 Schatzker J, McBroom R, Bruce D. The tibial plateau fracture. The Toronto experience 1968-1975. Clin Orthop Relat Res 1979;(138):94-104

11 Hohl M, Luck JV. Fractures of the tibial condyle; a clinical and experimental study. J Bone Joint Surg Am 1956; 38-A(5):1001-1018

12 Apley AG. Fractures of the lateral tibial condyle treated by skeletal traction and early mobilisation: a review of sixty cases with special reference to the long-term results. J Bone Joint Surg Br 1956;38-B(3):699-708

13 Apley AG. Fractures of the tibial plateau. Orthop Clin North Am 1979;10(1):61-74

14 Gausewitz S, Hohl M. The significance of early motion in the treatment of tibial plateau fractures. Clin Orthop Relat Res 1986;(202):135-138

15 Sarmiento A, Kinman PB, Latta LL, Eng P. Fractures of the proximal tibia and tibial condyles: a clinical and laboratory comparative study. Clin Orthop Relat Res 1979;(145):136-145

16 Scotland T, Wardlaw D. The use of cast-bracing as treatment for fractures of the tibial plateau. J Bone Joint Surg $\mathrm{Br}$ 1981;63B(4):575-578

17 Segal D, Mallik AR, Wetzler MJ, Franchi AV, Whitelaw GP. Early weight bearing of lateral tibial plateau fractures. Clin Orthop Relat Res 1993;(294):232-237

18 Ali AM, Burton M, Hashmi M, Saleh M. Outcome of complex fractures of the tibial plateau treated with a beam-loading ring fixation system. J Bone Joint Surg Br 2003;85(5):691-699

19 Keightley AJ, Nawaz SZ, Jacob JT, Unnithan A, Elliott DS, Khalil A. Ilizarov management of Schatzker IV to VI fractures of the tibial plateau. Bone Joint J 2015;97-B:1693-1697

20 Davies R, Holt N, Nayagam S. The care of pin sites with external fixation. J Bone Joint Surg Br 2005;87(5):716-719

21 Checketts RG, Otterburn M, Mac Eachern AG. Pin track infection; definition, incidence and prevention. Int J Orthop Trauma 1993;3(Suppl 3):16-18

22 Dendrinos GK, Kontos S, Katsenis D, Dalas A. Treatment of high-energy tibial plateau fractures by the Ilizarov circular fixator. J Bone Joint Surg 1996;78(5):710-717
23 Stokel EA, Sadasivan KK. Tibial plateau fractures: standardized evaluation of operative results. Orthopedics 1991;14(3):263-270

24 Benirschke SK, Agnew SG, Mayo KA, Santoro VM, Henley MB. Immediate internal fixation of open, complex tibial plateau fractures: treatment by a standard protocol. J Orthop Trauma 1992;6(1):78-86

25 Burri C, Bartzke G, Coldewey J, Muggler E. Fractures of the tibial plateau. Clin Orthop Relat Res 1979;(138):84-93

26 Moore TM, Patzakis MJ, Harvey JP. Tibial plateau fractures: definition, demographics, treatment rationale, and long-term results of closed traction management or operative reduction. J Orthop Trauma 1987;1(2):97-119

27 Boszotta H, Helperstorfer W, Kölndorfer G, Prünner K. Longterm results of surgical management of tibial head fractures [in German]. Aktuelle Traumatol 1993;23(4):178-182

28 Young MJ, Barrack RL. Complications of internal fixation of tibial plateau fractures. Orthop Rev 1994;23(2):149-154

29 Barei DP, Nork SE, Mills WJ, Henley MB, Benirschke SK. Complications associated with internal fixation of high-energy bicondylar tibial plateau fractures utilizing a two-incision technique. J Orthop Trauma 2004;18(10):649-657

30 Eggli S, Hartel MJ, Kohl S, Haupt U, Exadaktylos AK, Röder C. Unstable bicondylar tibial plateau fractures: a clinical investigation. J Orthop Trauma 2008;22(10):673-679

31 Rademakers MV, Kerkhoffs GM, Sierevelt IN, Raaymakers EL Marti RK. Operative treatment of 109 tibial plateau fractures: fiveto 27-year follow-up results. J Orthop Trauma 2007;21(1):5-10

32 Egol KA, Tejwani NC, Capla EL, Wolinsky PL, Koval KJ. Staged management of high-energy proximal tibia fractures (OTA types 41): the results of a prospective, standardized protocol. J Orthop Trauma 2005;19(7):448-455, discussion 456

33 Parameswaran AD, Roberts CS, Seligson D, Voor M. Pin tract infection with contemporary external fixation: how much of a problem? J Orthop Trauma 2003;17(7):503-507

34 Catagni MA, Ottaviani G, Maggioni M. Treatment strategies for complex fractures of the tibial plateau with external circular fixation and limited internal fixation. J Trauma 2007;63(5):1043-1053

35 Yu Z, Zheng L, Zhang Y, Li J, Ma B. Functional and radiological evaluations of high-energy tibial plateau fractures treated with double-buttress plate fixation. Eur J Med Res 2009;14(5):200-205

36 Lee JA, Papadakis SA, Moon C, Zalavras CG. Tibial plateau fractures treated with the less invasive stabilisation system. Int Orthop 2007;31(3):415-418

37 Oh CW, Oh JK, Kyung HS, et al. Double plating of unstable proximal tibial fractures using minimally invasive percutaneous osteosynthesis technique. Acta Orthop 2006;77(3):524-530

38 El Barbary H, Abdel Ghani H, Misbah H, Salem K. Complex tibial plateau fractures treated with Ilizarov external fixator with or without minimal internal fixation. Int Orthop 2005;29(3):182-185

39 Zecher SB, Danziger MB, Segal D, Foster T, Whitelaw GP, Covall DJ. Treatment of high-energy proximal tibial fractures using the Monticelli-Spinelli external fixator: a preliminary report. Am J Orthop 1996;25(1):49-54

40 Debnath UK, Jha DK, Pujari PK. Results of ring (Ilizarov) fixator in high energy Schatzker type VI fractures of proximal tibia. J Clin Orthop Trauma 2018;9(2):186-191

41 Taşkesen A, Demirkale İ, Okkaoğlu MC, Özdemir M, Bilgili MG, Altay M. Intraobserver and interobserver reliability assessment of tibial plateau fracture classification systems. Eklem Hastalik Cerrahisi 2017;28(3):177-181 